\title{
A community-based cluster randomized survey of noncommunicable disease and risk factors in a peri-urban shantytown in Lima, Peru
}

\author{
Kristen Heitzinger $^{1 *}$, Silvia M Montano ${ }^{2}$, Stephen E Hawes ${ }^{1}$, Jorge O Alarcón ${ }^{3}$ and Joseph R Zunt ${ }^{1,4}$
}

\begin{abstract}
Background: An estimated 863 million people-a third of the world's urban population-live in slums, yet there is little information on the disease burden in these settings, particularly regarding chronic preventable diseases.

Methods: From March to May 2012, we conducted a cluster randomized survey to estimate the prevalence of noncommunicable diseases (NCDs) and associated risk factors in a peri-urban shantytown north of Lima, Peru. Field workers administered a questionnaire that included items from the WHO World Health Survey and the WHO STEPS survey of chronic disease risk factors. We used logistic regression to assess the associations of NCDs and related risk factors with age and gender. We accounted for sampling weights and the clustered sampling design using statistical survey methods.
\end{abstract}

Results: A total of 142 adults were surveyed and had a weighted mean age of 36 years (range 18-81). The most prevalent diseases were depression (12\%) and chronic respiratory disease (8\%), while lifetime prevalence of cancer, arthritis, myocardial infarction, and diabetes were all less than $5 \%$. Fifteen percent of respondents were hypertensive and the majority (67\%) was unaware of their condition. Being overweight or obese was common for both genders (53\%), but abdominal obesity was more prevalent in women (54\% vs. $10 \%$ in men, $p<0.001$ ). Thirty-five percent of men binge drank and 34\% reported current smoking; these behaviors were less common among women (4\% binge drank, $p<0.001 ; 8 \%$ smoked, $p=0.002$ ). Increasing age was associated with an increased risk of abdominal obesity (Odds Ratio $(\mathrm{OR})=1.04,95 \% \mathrm{Cl}=1.01,1.07, \mathrm{p}=0.02)$, hypertension $(\mathrm{OR}=1.06,95 \% \mathrm{Cl}=1.02,1.10, \mathrm{p}=0.006$ ), arthritis $(\mathrm{OR}=1.07,95 \% \mathrm{Cl}=1.03,1.11, \mathrm{p}<0.001)$ and cancer $(\mathrm{OR}=1.13,95 \% \mathrm{Cl}=1.07,1.20, \mathrm{p}<0.001)$ in adjusted models. The prevalences of other NCDs and related risk factors were similar when stratified by age or gender.

Conclusions: This study underlines the important burden of noncommunicable disease in informal settlements in Peru and suggests that prevention and treatment interventions could be optimized according to age and gender.

Keywords: Peru, Slum, Shantytown, Noncommunicable disease

\section{Background}

In developing countries, an estimated 863 million people live in slums, areas characterized by poor quality or informal housing, unhealthy living conditions, poverty, and marginalization from the formal health sector [1]. Because slum dwellers represent a third of the urban population of low- and middle-income countries, addressing intra-urban health inequities is an important challenge facing cities in the developing world [1,2]. Little is known about the

\footnotetext{
*Correspondence: heitzk@uw.edu

'Department of Epidemiology, University of Washington, Seattle, WA, USA Full list of author information is available at the end of the article
}

burden of disease in slums and low-income informal settlements because, due to their unofficial status and lack of resources, they are more frequently excluded from governmental epidemiologic surveillance and research studies. Additionally, health inequalities between slums and adjacent urban areas may be masked by their inclusion in a single surveillance catchment area, which has led to repeated calls for more robust intra-urban morbidity and mortality data [2-6]. Drawing on social epidemiologic theory, a high prevalence of a range of noncommunicable diseases (cardiovascular and chronic respiratory disease, diabetes, mental illness, arthritis, and cancer) 
and related risk factors (overweight and obesity, poor nutrition, harmful drinking, smoking, and hypertension) is expected in a slum population due to the particularly adverse factors present within each component of the WHO conceptual framework of social determinants of health [7]. This framework conceptualizes disease risk and risk behaviors as being influenced by three major components: the socioeconomic-political context, the structural determinants of socioeconomic position, and the intermediary determinants of health [7]. Slums are characterized by urbanization, a lack of urban planning, overcrowding, and exclusion from social, health, and other services; such a socioeconomic-political context could be expected to have a higher prevalence of noncommunicable diseases due to the increased exposure to modifiable risk factors such as increased intake of fat and sugar associated with an urban lifestyle, few opportunities for physical activity due to limited space and insecurity, and a high prevalence of undiagnosed chronic conditions due to a lack of access to primary care services and health education. Slum dwellers also typically occupy a low socioeconomic position, and poverty and lower education levels are strongly linked to the development of NCDs [8]. Primary intermediary factors that are expected to be prevalent in a slum setting and contribute to the development of noncommunicable disease include inadequate access to sanitation and other infrastructure [5], insecure residential status [5], and exposure to violence and crime. In informal settlements, chronic noncommunicable diseases are at particular risk of going undetected by formal health registries until presentation in a late stage of disease or death; this has been attributed to a lack of access to health services and inadequate or inappropriate care when services are sought $[4,5]$. This pattern of health-seeking behavior typically results in an undue human cost and financial burden on existing health systems [3,4], underscoring the need for noncommunicable disease (NCD) data to advise health interventions targeting the urban poor.

In Peru, a middle-income country with a growing burden of NCD $[9,10]$, approximately forty percent of the population of the capital city, Lima, lives in low-income informal settlements. Limited research has investigated the epidemiology of NCD in populations living in informal settlements in Lima. The PERU-MIGRANT study was conducted in rural-to-urban migrants and lifelong urban residents living in a shantytown south of Lima [11]; although not designed to yield population-based disease estimates, data from the shantytown segment of the PERU-MIGRANT cohort provided evidence of a significant risk of cardiovascular disease. The prevalence of overweight or obesity, hypertension, and diabetes were estimated to be $67-71 \%, 13-30 \%$, and $2-5 \%$, respectively [12] and these results were similar to those of obesity and hypertension studies in other populations in periurban Lima $[13,14]$. A probable mood disorder (defined by a validated questionnaire) was identified in approximately a third (33-38\%) of the PERU-MIGRANT shantytown cohort, suggesting an important burden of mental illness in these informal settlements [15]. Although noncommunicable chronic respiratory disease has not been studied in an adult Peruvian shantytown population, research in adolescents indicates that this may additionally contribute to the NCD burden among adults living in these communities [16]. Prior studies in informal settlements in Peru have identified gender and age as determinants of NCD and related risk behaviors. The prevalences of binge drinking and smoking were significantly higher among men $[17,18]$, while women were more likely to be obese (assessed by either body mass index or waist circumference) and have metabolic syndrome $[13,19,20]$. Increasing age was associated with hypertension in an adult shantytown population [13]. As a part of a population-based health needs evaluation in a Peruvian shantytown, we aimed to measure the prevalence of NCD and related risk factors and to evaluate their associations with age and gender in order to inform the design of future interventions in this community.

\section{Methods}

\section{Study setting}

The study was conducted from March to May 2012 in Lomas de Zapallal, a shantytown located in a peri-urban area north of Lima, Peru. Lomas de Zapallal began to be settled approximately 20 years ago and has an estimated population of 30,000, although it continues to expand geographically into the uninhabited surrounding hills. A public water and sanitation system was installed in the community in 2009 and currently services about $90 \%$ of the population, but there is an important lack of other public services and access to health care. A research study in schoolchildren was previously conducted in this community [21], and a collaborative effort led by the Universidad Nacional Mayor de San Marcos, the University of Washington, and Architects Without Borders-Seattle to design and construct a healthier learning environment at a community school is ongoing [22].

\section{Study design and procedures}

Study subjects were sampled using a two-step cluster sampling method. A building density map of Lomas de Zapallal was used to divide the community into 30 clusters of approximately equal population size, and households were randomly selected from each cluster by identifying a random location within the cluster, interviewing the eligible household nearest to that location, and proceeding to interview adjacent eligible households until meeting the required number of households per cluster, according to the World Health Organization EPI Methodology [23]. We calculated a sample size of 135 
households was needed to yield prevalence estimates with a minimum precision of $\pm 12.5 \%$, assuming a design effect of 2.2 and given that, in contrast to the EPI Method, all clusters were sampled as compared to a random sample [24]. We therefore aimed to sample 4 or 5 households from each cluster in order to ensure a representative sample and adequate sample size. Adults aged 18 and older who spoke Spanish and who were able to comply with study procedures were eligible to participate and an adult household member was chosen from each household for study participation using a random number table. Three attempts were made to survey houses in which the selected respondent was initially unavailable. Houses were most frequently surveyed on Sundays in an effort to maximize the probability of contacting selected potential participants.

Informed consent was obtained from each subject prior to the start of any study procedures. Field workers administered a comprehensive health questionnaire regarding health history, behaviors, and sociodemographic information (Additional file 1). This questionnaire included selected questions from the World Health Survey and all of the core questions of the WHO STEPS survey on noncommunicable disease risk factors [25] with the exception of the questions regarding physical activity and biochemical measures, which were excluded to decrease the length of the interview. This questionnaire was pilot tested in a small group of community members having similar sociodemographic characteristics as the study population.

Anthropometric measures including height, weight, blood pressure, and waist circumference were collected for each subject. Participants were requested to remove their shoes prior to measurement of height and weight and were weighed wearing light clothing. To improve accuracy, blood pressure was measured with the subject seated and the mean of two measures (taken at least 3 minutes apart) was used in analyses. Waist circumference was not measured in women who reported currently being pregnant. Ethical approval for this study was obtained from the Institutional Review Board of the Universidad Nacional Mayor de San Marcos. The Institutional Review Board of the University of Washington determined that this study did not meet the federal definition of research and it was therefore exempt from review.

\section{Measures}

NCD conditions were defined as follows:

1) Depression, chronic respiratory disease, arthritis, cancer, and myocardial infarction: The presence of one of these conditions was defined as an affirmative answer to the question "have you ever been told by a doctor or other health professional that you have or had depression, chronic respiratory disease, arthritis, cancer or myocardial infarction?"

2) Diabetes: Self-reported diabetes (an affirmative answer to the question "have you ever been told by a doctor or other health professional that you have diabetes?") and displayed diabetes medications to the field worker for documentation.

Physiological risk factors for NCD were defined as follows:

1) Obesity: We used two measures to define obesity: body mass index (BMI) and abdominal obesity. Per World Health Organization (WHO) guidelines, BMI was categorized as normal weight $(18.5 \leq \mathrm{BMI} \geq$ 24.9), overweight ( $25.0 \leq \mathrm{BMI} \geq 29.9)$ or obese $(\mathrm{BMI} \geq 30.0)[26]$. Abdominal obesity was measured to complement the definition of obesity using BMI because, although BMI is a widely used measure of obesity and has a well established association with cardiovascular disease (CVD), diabetes, and cancer risk, there is evidence that abdominal obesity better predicts CVD risk [27]. Per the WHO definition, waist circumference of $>102 \mathrm{~cm}$ in men and $>88 \mathrm{~cm}$ in women was defined as having abdominal obesity [27]. In a 2010 study in Peru, cutoffs of $>97 \mathrm{~cm}$ in men and $>87 \mathrm{~cm}$ in women were optimal to detect subclinical and manifest cardiovascular disease [28]; we therefore included both definitions in our analyses.

2) Hypertension: Participants were considered as having hypertension if the mean systolic blood pressure measure was $\geq 140 \mathrm{mmHg}$ and/or the mean diastolic blood pressure measure was $\geq 90 \mathrm{mmHg}$. Participants were also considered as having hypertension if they reported a physician diagnosis and could present hypertensive medications to the field worker for documentation.

Behavioral risk factors for NCD were defined as follows:

1) Tobacco use: Participants were questioned about current smoking (yes/no) and frequency of smoking (daily/less frequent). Daily smokers were questioned about frequency of use of specific tobacco products and about smoking history.

2) Harmful alcohol consumption: Participants were questioned about lifetime alcohol use, frequency of alcohol use within the previous 12 months, and frequency of alcohol use within the past 30 days. Harmful alcohol consumption (binge drinking) was defined for women as having consumed 4 or more 
standard alcoholic drinks on a single occasion in the last 30 days, and for men, as having consumed 5 or more drinks. Pictures of examples of standard alcoholic drinks were shown to participants to clarify quantities of alcohol.

3) Inadequate fruit and vegetable consumption: Participants were asked to estimate the number of days they consumed fruit and the average number of portions of fruit consumed on one of those days. Similar questions were asked regarding vegetable consumption. The average daily number of portions of fruits and vegetables consumed was calculated from these variables. Daily fruit and vegetable consumption of less than 5 portions was considered to be inadequate, per the WHO recommendations of NCD behavioral risk factor indicators [8].

\section{Statistical analysis}

We used statistical survey methods (the svy command in STATA 13.1) to account for survey weights and the clustered sampling design. Because age and sex were collected for all adults in contacted households including those that did not participate, the age and sex distribution of the participants was compared to those of the non-participants and the data were weighted back to the population sex distribution (49.9\% male, 50.1\% female) to correct for the non-response of males selected to participate. Descriptive statistics were generated using cross-tabulations and Chi-square tests were used to assess significant differences between groups. Logistic regression was used to determine whether participant age and sex were associated with the odds of chronic disease diagnosis or chronic disease risk behaviors. Odds ratios and $95 \%$ confidence intervals (95\% CIs) were estimated for these associations. Sex and (continuous) age were included as a priori confounders in adjusted models of the associations of sex and age, respectively. Variables known to be associated with selected NCD and risk factors were also considered as potential confounders in adjusted models; these variables included educational attainment (none, completed elementary school, completed high school, and completed technical school or university), income earned in the previous week (categorized by quartile), occupation (formal worker (government or private sector), independent worker, student, housewife, unemployed), marital status (single/divorced/ widowed, married/cohabitating), health insurance (yes/ no), migration directly to the community from a location outside of the Lima metropolitan area, overcrowding (as measured by the number of people living in the home), access to an improved water source, and access to improved sanitation. A forward stepwise approach was used to identify confounding variables and those variables having a corresponding p-value of less than 0.05 were retained in the final model. Data were collected and managed using REDCap electronic data capture tools [29] and analyzed using STATA, version 13.1 (StataCorp, College Station, TX). A significance level of 0.05 was used for all hypothesis testing.

\section{Results \\ Study population}

211 households were visited by field workers, with 193 households providing basic demographic information (age and gender of household members) and 145 households completing study procedures. Three households were excluded from the final sample because their inclusion would have resulted in oversampling of the cluster, yielding a final sample of 142 households for analysis.

Seventy-four percent of selected household respondents were successfully contacted and accepted to participate, with females being significantly more likely to participate as compared to males $(85.3 \%$ vs. $55.8 \%$; $\mathrm{p}<$ $0.001)$. Males were more likely to be unsuccessfully contacted $(22.1 \%$ vs. $6.9 \%, \mathrm{p}=0.001)$ and were more likely to refuse participation $(22.1 \%$ vs. $7.8 \%, \mathrm{p}=0.001)$ and as compared to females. Study participants and non-participants did not differ significantly by age $(\mathrm{p}=0.46)$.

Fifty percent of the study population was female, and the mean age was 35.9 years (95\% CI: 32.3, 39.6). The mean household size was 5.4 members $(95 \%$ CI $4.8,5.9)$, half of subjects had an elementary school education or less, and 59.2\% were married or cohabitating. Household income ranged from 30 to 900 soles (about US\$12-346) weekly, with a mean of 268 soles (about US\$100). Subject sociodemographic characteristics are summarized in Table 1.

Although nearly all respondents (98.6\%) reported receiving medical care the last time they (or a child under age 13) needed it, improved access to medical care was the most frequently cited change respondents desired with regard to the health of adults living in their community (cited by $48.4 \%$ of respondents). Environmental improvements (paved roads, sidewalks, and the creation of green space) and improvements in health care quality were the next most frequently desired changes. The NCDs or NCD-related risk factors most commonly cited as important adult health issues in the community were poor nutrition, diabetes, cancer, and alcohol abuse.

\section{Prevalence of noncommunicable disease and risk factors}

The most prevalent self-reported NCD diagnoses were depression (11.8\%) and chronic respiratory disease (8.4\%; Table 2). The prevalence of cancer, arthritis, myocardial infarction, and diabetes were all less than $5 \%$ (Table 2). Overweight/obesity and abdominal obesity were highly prevalent, as $52.6 \%$ of participants were overweight or obese and approximately $35 \%$ of participants had 
Table 1 Characteristics of 142 adults in a shantytown in Lima, Peru, 2012

\begin{tabular}{|c|c|c|c|c|}
\hline & $\begin{array}{c}\text { Total } \\
(\mathrm{N}=142)\end{array}$ & $\begin{array}{c}\text { Male } \\
(\mathrm{N}=43)\end{array}$ & $\begin{array}{l}\text { Female } \\
(\mathrm{N}=99)\end{array}$ & \\
\hline Characteristic & $\%$ & $\%$ & $\%$ & $\mathrm{p}$-value \\
\hline Age (years) & & & & 0.23 \\
\hline $18-25$ & 25.9 & 25.7 & 26.0 & \\
\hline $26-35$ & 32.4 & 37.7 & 27.2 & \\
\hline $36-45$ & 22.5 & 14.1 & 30.8 & \\
\hline $46+$ & 19.3 & 22.5 & 16.0 & \\
\hline Marital status & & & & 0.10 \\
\hline Single & 36.8 & 46.3 & 27.4 & \\
\hline Married & 18.8 & 22.1 & 15.5 & \\
\hline Separated & 3.0 & 2.3 & 3.6 & \\
\hline Widowed & 1.0 & 0.0 & 2.1 & \\
\hline Cohabitating & 40.4 & 29.3 & 51.5 & \\
\hline $\begin{array}{l}\text { Highest level of } \\
\text { education attained }\end{array}$ & & & & 0.81 \\
\hline Less than primary & 14.0 & 13.7 & 14.3 & \\
\hline Primary & 36.4 & 33.9 & 38.8 & \\
\hline Secondary & 43.1 & 47.1 & 39.2 & \\
\hline Technical institute & 5.8 & 5.3 & 6.3 & \\
\hline University (non-technical) & 0.7 & 0.0 & 1.4 & \\
\hline $\begin{array}{l}\text { Weekly household } \\
\text { income quartile (soles) }\end{array}$ & & & & 0.69 \\
\hline$<125$ & 22.3 & 20.6 & 24.0 & \\
\hline $125-200$ & 31.8 & 26.9 & 36.7 & \\
\hline $201-300$ & 22.7 & 24.7 & 20.8 & \\
\hline$>300$ & 23.1 & 27.8 & 18.5 & \\
\hline $\begin{array}{l}\text { Mean household size } \\
(95 \% \mathrm{Cl})\end{array}$ & $5.4(4.8-5.9)$ & $5.5(4.7-6.3)$ & $5.3(4.7-5.9)$ & 0.05 \\
\hline Health insurance $^{\dagger}$ & 30.4 & 24.4 & 36.4 & 0.16 \\
\hline $\begin{array}{l}\text { Migration from outside } \\
\text { Lima-Callao }\end{array}$ & 42.7 & 49.0 & 36.4 & 0.21 \\
\hline
\end{tabular}

${ }^{\top}$ Types of health insurance reported included Essalud, Seguro Integral de Salud (SIS), police or armed forces insurance, and private health insurance.

abdominal obesity (Table 2). Hypertension was less common, with a $15 \%$ prevalence (Table 2). Of participants who met the definition for hypertension, only $32.8 \%$ were aware of their condition. With regard to NCD behavioral risk factors, $21.1 \%$ of the population reported current smoking, but less than $1 \%$ reported doing so daily. Although only $39.3 \%$ of the population reported alcohol consumption within the previous month, about half (51.0\%) of alcohol consumers binge drank on at least one occasion during that time period. Fruit and vegetable consumption was low overall, with subjects consuming an average of only one portion of fruit (mean 1.37, 95\% CI $1.03,1.70$ ) and one portion of vegetables (mean $0.99,95 \%$ CI $0.79,1.20$ daily). The large majority (91.6\%) did not consume the recommended 5 portions of fruits and vegetables daily.

\section{The effects of age and sex}

We sought to identify the age and gender differences in the prevalence of noncommunicable disease diagnoses and risk factors in the study population (Figure 1, Figure 2). In univariate analysis, women were significantly more likely than men to be overweight or obese (65.2 vs. $40.0 \%, \mathrm{p}=0.02)$, and to have abdominal obesity $(54.3$ vs. $9.5 \%$ per WHO cutoffs, $\mathrm{p}=0.002 ; 55.2$ vs. $16.4 \%$ per Peruvian cutoffs, $\mathrm{p}=0.001$ ). In models adjusted for age and other confounding variables, the prevalence of overweight and obesity did not differ significantly by gender, however, females were six to thirteen times more likely to have abdominal obesity, depending on which definition of abdominal obesity was used (OR using WHO definition $=13.73,95 \% \mathrm{CI}=(2.71,64.75)$, $\mathrm{p}=0.002$; OR using Peruvian data definition $=6.38$, 95\% CI $=1.71,23.82, \mathrm{p}=0.007$; Table 3 ). In univariate analysis, men were more likely to report current smoking (34.3 vs. $7.9 \%, \mathrm{p}=0.002)$ or binge drinking (34.7 vs. $4.1 \%, \mathrm{p}<0.001)$. These differences correspond to a five-fold increased likelihood of current smoking ( $\mathrm{OR}=6.21,95 \%$ $\mathrm{CI}=1.83,21.10, \mathrm{p}=0.005)$ and thirteen-fold increased risk of binge drinking $(\mathrm{OR}=14.02,95 \% \mathrm{CI}=3.66$, 53.71, $\mathrm{p}<0.001)$ as compared to females in adjusted models (Table 3). Men and women did not differ significantly with respect to the prevalence of other chronic disease conditions or risk factors although the association between gender and cancer risk could not be evaluated due to small numbers of cases. In models adjusted for gender and other confounding variables, increasing age was associated with an increased risk of abdominal obesity (WHO definition; Odds Ratio (OR) $=1.04,95 \% \mathrm{CI}=1.01,1.07, \mathrm{p}=0.01)$, hypertension $(\mathrm{OR}=1.06,95 \% \mathrm{CI}=1.02,1.10, \mathrm{p}=0.006)$, arthritis $(\mathrm{OR}=1.08,95 \% \mathrm{CI}=1.04,1.12, \mathrm{p}=0.001$ per year $)$, and cancer $(\mathrm{OR}=1.13,95 \% \mathrm{CI}=1.07,1.20, \mathrm{p}=0.001)$. There were no other significant differences in the prevalence of NCD or related risk factors by age (Tables 3 and 4).

\section{Discussion}

In the context of a community health needs evaluation, we investigated the prevalence and age and gender distribution of noncommunicable disease in a peri-urban shantytown in Peru. Overall, there was a low prevalence of self-reported, diagnosed noncommunicable disease, although the prevalences of depression (12\%) and chronic respiratory disease in the population (8\%) signal that these conditions may contribute significantly to the NCD burden. Perhaps most alarming was the high frequency of excess weight, particularly among women; our findings of a 53\% prevalence of overweight/obesity overall and 54\% prevalence 
Table 2 Noncommunicable disease diagnoses and risk factors among adults in a shantytown in Lima, Peru, 2012

\begin{tabular}{|c|c|c|c|c|c|c|c|}
\hline \multirow[b]{2}{*}{ Characteristic } & \multicolumn{2}{|c|}{ Total $(\mathrm{N}=142)$} & \multicolumn{2}{|c|}{ Male $(\mathrm{N}=43)$} & \multicolumn{2}{|c|}{ Female $(\mathrm{N}=99)$} & \multirow[b]{2}{*}{ p-value } \\
\hline & $\%$ & $(95 \% \mathrm{Cl})$ & $\%$ & $(95 \% \mathrm{Cl})$ & $\%$ & $(95 \% \mathrm{Cl})$ & \\
\hline Nutritional status (based on BMI) & & & & & & & 0.03 \\
\hline Normal weight & 47.4 & $(37.1,57.6)$ & 60.0 & $(43.6,76.4)$ & 34.8 & $(23.1,46.5)$ & \\
\hline Overweight & 39.5 & $(30.1,48.9)$ & 32.8 & $(16.6,49.0)$ & 46.2 & $(36.4,56.1)$ & \\
\hline Obese & 13.1 & $(8.2,18.1)$ & 7.2 & $(0.0,14.9)$ & 19.0 & $(11.8,26.2)$ & \\
\hline Abdominal obesity (WHO definition) & 31.9 & $(25.0,38.9)$ & 9.5 & $(1.0,18.1)$ & 54.3 & $(40.0,68.5)$ & $<0.001$ \\
\hline Abdominal obesity (Peruvian data definition) & 35.8 & $(28.1,43.5)$ & 16.4 & $(5.3,27.5)$ & 55.2 & $(40.9,69.4)$ & 0.001 \\
\hline Hypertension & 14.9 & $(6.6,23.3)$ & 19.4 & $(6.0,32.8)$ & 10.5 & $(4.0,17.0)$ & 0.10 \\
\hline Diabetes & 2.7 & $(0.0,5.0)$ & 1.5 & $(0.0,4.6)$ & 3.8 & $(0.0,7.8)$ & 0.42 \\
\hline Depression & 11.8 & $(4.3,19.4)$ & 6.9 & $(0.0,16.4)$ & 16.8 & $(6.6,26.9)$ & 0.17 \\
\hline Chronic respiratory disease & 8.4 & $(1.6,15.1)$ & 9.3 & $(0.0,20.1)$ & 7.4 & $(1.6,13.3)$ & 0.71 \\
\hline Arthritis & 3.6 & $(0.0,7.3)$ & 1.9 & $(0.0,5.9)$ & 5.2 & $(0.0,11.8)$ & 0.40 \\
\hline Cancer & 0.5 & $(0.0,1.6)$ & 0.0 & $(\mathrm{NA})$ & 1.0 & $(0.0,3.1)$ & 0.32 \\
\hline Myocardial infarction & 1.9 & $(0.0,5.0)$ & 3.1 & $(0.0,9.2)$ & 0.7 & $(0.0,2.1)$ & 0.26 \\
\hline Current smoking & 21.1 & $(13.5,28.6)$ & 34.3 & $(18.7,49.9)$ & 7.9 & $(1.9,13.9)$ & 0.002 \\
\hline Binge drinking in the past month & 19.4 & $(12.0,26.8)$ & 34.7 & $(20.7,48.6)$ & 4.1 & $(0.0,8.3)$ & $<0.001$ \\
\hline Inadequate fruit and vegetable consumption & 91.6 & $(86.2,96.9)$ & 89.7 & $(79.7,99.8)$ & 93.4 & $(88.8,98.0)$ & 0.47 \\
\hline
\end{tabular}

of abdominal obesity in women indicate a major risk for development of a noncommunicable disease. With regard to other risk factors for NCD, inadequate fruit and vegetable consumption by the majority (92\%) of participants and a $15 \%$ prevalence of hypertension-the majority undiagnosed-in this population demonstrate the importance of these risk factors as potential contributors to NCD risk in this community.

Our estimates of NCD morbidity are generally similar to those of prior studies conducted in informal settlements in Peru $[12,15,16]$. However, our population prevalence of depression was substantially lower than the prevalence of probable mental illness estimated in the PERU-MIGRANT shantytown cohort (12 vs. 33-38\%) [15]. This difference could be explained by our definition of depression as having received a diagnosis of depression from a healthcare provider, which likely underestimated the prevalence of depression in our population. The difference also may be due to the fact that in the PERU-MIGRANT study, current rather than lifetime prevalence was measured; recall bias may have resulted in underreporting of lifetime depression diagnoses. The measure employed in the PERU-MIGRANT study may additionally have resulted in an overestimate of population depression prevalence due to its inability to

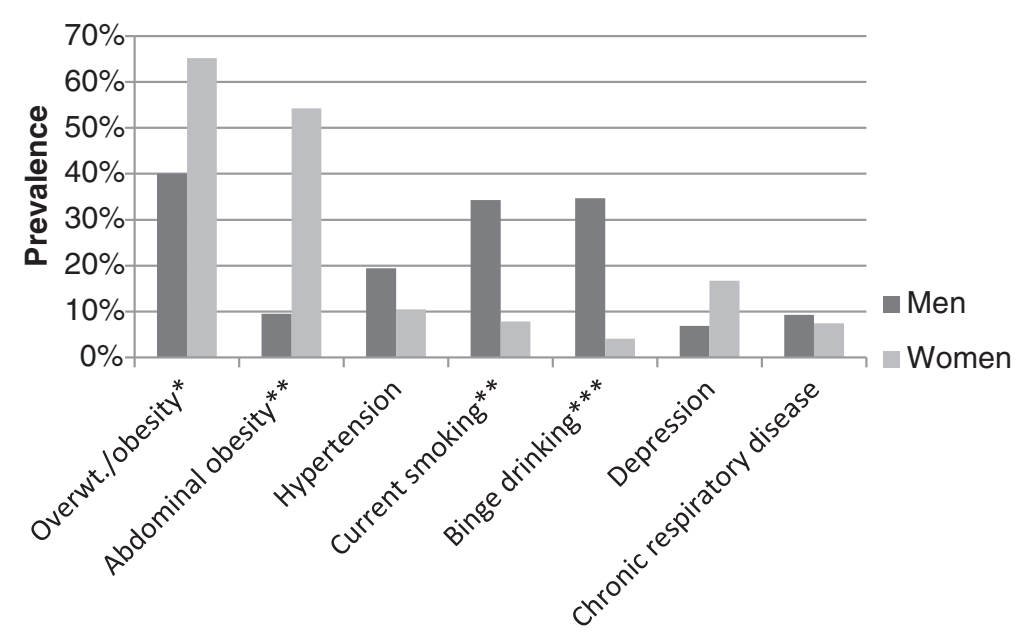

Figure 1 Gender-specific prevalences of selected noncommunicable disease diagnoses and risk factors in a Peruvian shantytown, 2012. Results are shown for univariate logistic regression models. Significance codes: $p<0.001^{{ }^{\prime * * * \prime},}, p<0.01^{\text {}^{* * \prime},}, p<0.05^{{ }^{\prime * \prime},}, p>0.05^{\prime \prime}$. 


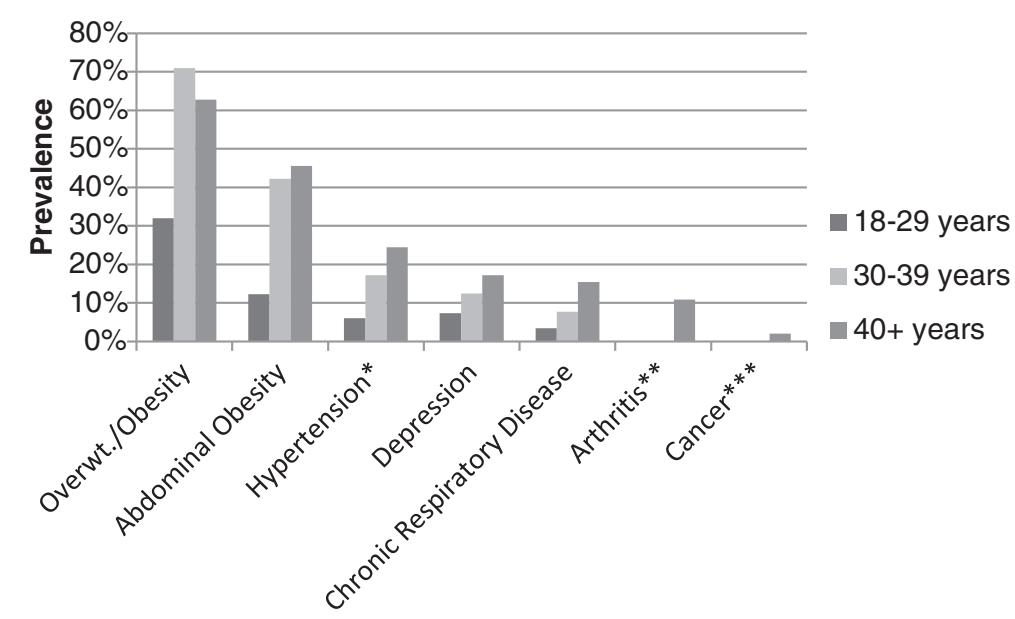

Figure 2 Age-specific prevalences of selected noncommunicable disease conditions and risk factors in a Peruvian shantytown, 2012. Results are shown for univariate logistic regression models, with significant p-values for the trend in continuous age denoted. Significance codes:

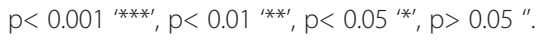

distinguish between depression and anxiety [15]. Our estimate of lifetime depression prevalence is, however, similar to that estimated for the adult population of metropolitan Lima (18\%) [30]. As compared to mental health research conducted in slum populations outside of Peru, the prevalence of depression in the present study is less than half of that measured in older adults [31] and women [32] living in slums in India, and is lower than the prevalence of self-rated poor or fair mental well-being measured in two Bangladeshi slum populations $[33,34]$. These differences are likely attributable in part to the fact that in other studies the definition of depression or poor mental health did not require having received a physician diagnosis.

The only other study to our knowledge to report on the prevalence of chronic respiratory disease in a adult slum population, conducted in India, found similar prevalences of asthma symptoms (10\%) and chronic bronchitis (8.5\%) [35]. In this population, asthma symptomology, but not chronic bronchitis, was associated with female gender and increasing age. It is possible that the heterogeneity of conditions captured by our chronic respiratory disease measure obscured condition-specific gender and age differences that may have been present in our study population.

The prevalence of arthritis measured in the present study is slightly lower than the prevalence of osteoarthritis of the knees found in a Bangladeshi adult urban slum population [36], which may be attributable to differences in the working conditions and physical demands of occupations, particularly for men, in these populations. Diabetes prevalences estimated in slum populations in Kenya [37,38] and India [39] are similar to that of the present study while they are higher in Bangladesh (8\%) [40]

Table 3 Associations of sex and age with noncommunicable disease risk factors in a Peruvian shantytown, 2012

\begin{tabular}{|c|c|c|c|c|c|c|c|c|}
\hline & $\begin{array}{l}\text { Overweight/ } \\
\text { obesity }^{\mathrm{a}}\end{array}$ & Obesity $^{b}$ & $\begin{array}{c}\text { Abdominal } \\
\text { obesity } \text { b }^{\mathbf{b}} \text { (WHO } \\
\text { definition) }\end{array}$ & $\begin{array}{c}\text { Abdominal } \\
\text { obesity (Peruvian } \\
\text { data definition) }\end{array}$ & Hypertension $^{c}$ & $\begin{array}{l}\text { Current } \\
\text { smoking }\end{array}$ & $\begin{array}{c}\text { Binge } \\
\text { drinking }^{d}\end{array}$ & $\begin{array}{l}\text { Inadequate fruit } \\
\text { and vegetable } \\
\text { consumption }\end{array}$ \\
\hline & $\begin{array}{c}\text { Multivariable } \\
\text { OR }\end{array}$ & $\begin{array}{c}\text { Multivariable } \\
\text { OR }\end{array}$ & $\begin{array}{c}\text { Multivariable } \\
\text { OR }\end{array}$ & $\begin{array}{c}\text { Multivariable } \\
\text { OR }\end{array}$ & $\begin{array}{c}\text { Multivariable } \\
\text { OR }\end{array}$ & $\begin{array}{c}\text { Multivariable } \\
\text { OR }\end{array}$ & $\begin{array}{c}\text { Multivariable } \\
\text { OR }\end{array}$ & $\begin{array}{c}\text { Multivariable } \\
\text { OR }\end{array}$ \\
\hline & $(95 \% \mathrm{Cl})$ & $(95 \% \mathrm{Cl})$ & $(95 \% \mathrm{Cl})$ & $(95 \% \mathrm{Cl})$ & $(95 \% \mathrm{Cl})$ & $(95 \% \mathrm{Cl})$ & $(95 \% \mathrm{Cl})$ & $(95 \% \mathrm{Cl})$ \\
\hline Female & 2.15 & 2.51 & $13.03^{* *}$ & $7.41^{* *}$ & 0.44 & $016^{* *}$ & $0.07^{* * *}$ & 1.76 \\
\hline Gender & $(0.80,5.78)$ & $(0.63,10.05)$ & $(2.76,61.50)$ & $(2.10,26.20)$ & $(0.18,1.12)$ & $(0.05,0.55)$ & $(0.02,0.27)$ & $(0.42,7.29)$ \\
\hline Age & 1.01 & 1.00 & $1.04^{*}$ & $1.04^{*}$ & $1.06^{* *}$ & 0.98 & 0.97 & 1.01 \\
\hline (Years) & $(0.98,1.05)$ & $(0.97,1.04)$ & $(1.00,1.07)$ & $(1.01,1.08)$ & $(1.02,1.10)$ & $(0.96,1.01)$ & $(0.93,1.01)$ & $(0.96,1.06)$ \\
\hline
\end{tabular}

All models of associations of gender and risk factors are adjusted for continuous age.

All models of associations of age and risk factors are adjusted for gender.

${ }^{a}$ Model additionally adjusted for marital status, migration, and health insurance.

${ }^{\mathrm{b}}$ Model additionally adjusted for marital status.

cModel additionally adjusted for household crowding.

${ }^{\mathrm{d}}$ Model additionally adjusted for improved sanitation.

Significance codes: $\mathrm{p}<0.001^{* * * \prime,} \mathrm{p}<0.01^{\prime * * \prime}, \mathrm{p}<0.05^{\prime * \prime}, \mathrm{p}>0.05^{\prime \prime}$. 
Table 4 Associations of sex and age with noncommunicable disease conditions in a Peruvian shantytown, 2012

\begin{tabular}{|c|c|c|c|c|c|c|}
\hline & $\begin{array}{c}\text { Depression } \\
\text { Multivariable OR } \\
(95 \% \mathrm{Cl})\end{array}$ & $\begin{array}{c}\text { Chronic respiratory disease } \\
\text { Multivariable OR } \\
(95 \% \mathrm{Cl})\end{array}$ & $\begin{array}{c}\text { Arthritis } \\
\text { Multivariable OR } \\
(95 \% \mathrm{Cl})\end{array}$ & $\begin{array}{c}\text { Cancer } \\
\text { Multivariable OR } \\
(95 \% \mathrm{Cl})\end{array}$ & $\begin{array}{c}\text { Myocardial infarction } \\
\text { Multivariable OR } \\
(95 \% \mathrm{Cl})\end{array}$ & $\begin{array}{c}\text { Diabetes }^{\mathrm{a}} \\
\text { Multivariable OR } \\
(95 \% \mathrm{Cl})\end{array}$ \\
\hline Female & 2.74 & 0.80 & 4.02 & Could not be & 0.22 & 2.58 \\
\hline Gender & $(0.59,12.74)$ & $(0.21,3.04)$ & $(0.16,100.26)$ & calculated & $(0.01,4.45)$ & $(0.18,37.20)$ \\
\hline Age & 1.00 & 1.01 & $1.07^{* * *}$ & $1.13^{* * *}$ & 0.98 & 1.06 \\
\hline (Years) & $(0.97,1.03)$ & $(0.98,1.04)$ & $(1.03,1.11)$ & $(1.07,1.20)$ & $(0.95,1.01)$ & $(0.99,1.14)$ \\
\hline
\end{tabular}

All models of associations of gender and disease conditions are adjusted for continuous age.

All models of associations of age and disease conditions are adjusted for gender.

${ }^{a}$ Model additionally adjusted for household crowding.

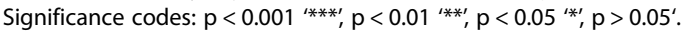

and in an elderly Indian population (18\%) [41]. The paucity of cancer and myocardial infarction data from adult slum populations limits our ability to compare our findings regarding these outcomes.

Similarly to the prevalences of NCD conditions, the prevalences of risk factors for NCD estimated in this study are also comparable to those of prior studies in Peruvian informal settlements $[12,13,17,18,42]$. Our population prevalences of hypertension, overweight status, and obesity are slightly lower than those estimated for the PERU-MIGRANT shantytown cohort, however, the age-specific prevalences of these conditions in our population suggest that this difference is due to the slightly younger age of our study population. The prevalence of overweight and obesity estimated in this study was similar to that of other slum populations in Nigeria [43] and Kenya [37] but greater than that of a different Kenyan slum [44] and greater than Indian [39] and Bangladeshi [40] slum populations. These differences in the prevalence of overweight and obesity are likely due to a number of factors and may be related to the progress of the epidemiologic transition or characteristics specific to the particular slum setting. In contrast to the findings of the PERU-MIGRANT study [19], women did not have a significantly greater prevalence of obesity defined by BMI, however, the greater prevalences of abdominal obesity in women in our study suggest that this finding may have been due to the limitations of our sample size rather than a true difference in results. Like the finding of the current study, research in Kenyan [37,45] and Indian [39] slum populations found that women were more likely to have abdominal obesity while data from an Indian study provided evidence that abdominal obesity increased with age [39]. Age and gender associations with abdominal obesity were not assessed in the Nigerian or Bangladeshi studies and the association with age was not assessed in the Kenyan studies. The association we observed between female gender and abdominal obesity may be the result of gender norms affecting individual health-related behaviors such as physical activity. The association of abdominal obesity with age likely reflects the cumulative effects of unhealthy diet and insufficient physical activity over the lifespan which we did not investigate in the current study but may further investigate in future NCD studies in this population.

Comparing to slum populations outside of Peru, our population prevalence of hypertension was similar to that of populations in Kenya [45] and India [39], but was considerably less than the prevalence of $38 \%$ measured in a $\mathrm{Ni}$ gerian slum population [43] and considerably greater than the approximately $2 \%$ prevalence measured in a Bangladeshi slum [40]. As in the present study, hypertension was associated with increasing age in previous studies conducted in Peru [13], India [39], Kenya [45] and Nigeria [43]; this association was not evaluated in the Bangladeshi population. This age-related trend with hypertension likely reflects the stiffening of blood vessels through ageing, although it could also reflect uncontrolled confounding by factors that are associated both with age and hypertension.

Like other research in informal settlements in Peru, we found a greater prevalence of binge drinking and smoking among men $[17,18]$, which is similar to patterns of hazardous drinking and tobacco use in the adult population of the Lima metropolitan area [30] and which likely reflect differences in gender-based social expectations [18]. Similar gender differences in hazardous drinking and tobacco use have been noted in non-Peruvian slum populations $[37,39,43,45]$.

Because this study was conducted in the context of a broader health needs assessment, we designed our study instruments with the goal of balancing three objectives: 1) to capture a large number of health indicators on a broad spectrum of topics to describe the community burden of disease, 2) to collect valid measures of NCDrelated variables, and 3) to limit participant burden. Although we did obtain an overall picture of the burden of communicable and noncommunicable disease in this population, we were unable to collect a number of NCD and NCD risk-related variables or to use more timeconsuming, higher validity measures for each variable. The self-reported nature of the NCD variables, for example, likely led to underestimates of the prevalence of 
these diseases. With regard to NCD-related risk behaviors, only one aspect of unhealthy diet-adequate fruit and vegetable consumption-was measured, and we did not measure this variable using a high validity measure such as a food frequency questionnaire. Future investigations of diet-related NCD risk factors could additionally collect information regarding salt intake and saturated fat and trans-fat consumption, two other important aspects of diet-related NCD risk [8]. Due to concerns about survey length, we also did not measure physical activity in our survey, and the inclusion of this risk factor will be important in future community surveys both as an important risk behavior related to NCD and to measure the impact of interventions and improvements in community infrastructure. The inclusion of biochemical measures would have allowed us to better measure certain NCDs and associated risk factors such as diabetes and high cholesterol and therefore should be included in future NCD studies in this community. Although our population estimates were weighted to account for the greater proportion of non-participation among males selected to participate in this study, the difficulty we encountered in contacting and in obtaining consent from potential male participants highlights the importance of coordinating the schedule of data collection with the availability of less accessible segments of the population and the potential need for participation incentives in order to reduce underrepresentation of men in the sampling of similar populations. Our relatively small sample size may have precluded the identification of other differences in NCD and risk factor prevalence by age and gender.

Despite these limitations, this study had a number of strengths. To our knowledge, this is the first populationbased study to describe the burden of noncommunicable disease and related risk factors in a Peruvian shantytown. Aside from the randomized sampling and novel population of this study, other strengths include the objective measurement of BMI, abdominal obesity, and hypertension, and the use of a standardized questionnaire to assess NCD risk behaviors.

\section{Conclusions}

Our study findings provide a panorama of the prevalence of noncommunicable disease and related risk factors in informal settlements in Peru, highlighting the alarming frequency of overweight status and obesity. This study also identified age and gender as determinants of a number of NCDs and risk behaviors, thereby lending support to observations that health interventions in informal settlements may be optimized by age- and gender-specific approaches [46]. Among men, the approximately $35 \%$ prevalences of binge drinking and tobacco use highlight these behaviors as potential foci of NCD prevention interventions. Effective interventions are needed to reduce NCD in these communities. Specifically, community-based interventions comprising primary prevention, detection, and treatment of noncommunicable disease such as the cardiovascular disease intervention package currently being tested in slum communities in Nairobi, Kenya [47] may offer a potential way forward. Future research on interventions to decrease NCD and NCD risk factor prevalence should also assess costeffectiveness and sustainability in order to ensure future reductions in the NCD disease burden. Investment in research to identify low-cost interventions is crucial to avoid the far higher long-term cost of continued neglect of the urban poor in the developing world.

\section{Additional file}

Additional file 1: Noncommunicable diseases and risk factors survey.

\section{Abbreviations}

BMI: Body mass index; NCD: Noncommunicable disease; WHO: World Health Organization.

\section{Competing interests}

The authors declare that they have no competing interests. Dr. Silvia Montano is an employee of the U.S. Government. This work was prepared as part of her official duties. Title 17 U.S.C. $\$ 105$ provides that 'Copyright protection under this title is not available for any work of the United States Government'. Title 17 U.S.C. §101 defines a U.S. Government work as a work prepared by a military service member or employee of the U.S. Government as part of that person's official duties. The views expressed in this manuscript are those of the authors and do not necessarily reflect the official policy of position of the Department of the Navy, Department of Defense, nor the U.S. government.

\section{Authors' contributions}

All authors participated in the design of the study. $\mathrm{KH}$ conceived of the study, supervised and participated in data collection, performed the statistical analysis and drafted the manuscript. SM and JA assisted in the coordination of the data collection. SM, SH, JA, and JZ provided critical feedback on drafts. All authors read and approved the final manuscript.

\section{Acknowledgements}

We would like to express our gratitude to our study participants and the Lomas de Zapallal community for their support of this study. We would also like to thank the Sociedad Cientifica de San Fernando, Omar and Carlos Maguiña, and José Viñoles for their valuable contributions to data collection and Thanh Ton for her insights regarding study design. This work was supported by the National Institutes of Health Office of the Director, Fogarty International Center, Office of AIDS Research, National Cancer Center, National Eye Institute, National Heart, Blood, and Lung Institute, National Institute of Dental and Craniofacial Research, National Institute On Drug Abuse, National Institute of Mental Health, National Institute of Allergy and Infectious Diseases, and National Institutes of Health Office of Women's Health and Research through the Fogarty International Clinical Research Scholars and Fellows Program at Vanderbilt University (R24 TW007988) and the American Relief and Recovery Act.

\section{Author details}

${ }^{1}$ Department of Epidemiology, University of Washington, Seattle, WA, USA. ${ }^{2}$ U.S. Naval Medical Research Unit No. 6, Callao, Peru. ${ }^{3}$ Instituto de Medicina Tropical "Daniel A. Carrión", Universidad Nacional Mayor de San Marcos, Lima, Peru. ${ }^{4}$ Departments of Neurology, Global Health, and Medicine, University of Washington, Seattle, WA, USA. 
Received: 22 September 2013 Accepted: 9 May 2014

Published: 21 May 2014

\section{References}

1. UN-Habitat: State of the world's cities 2012/2013: prosperity of cities. In Book State of the World's Cities 2012/2013: Prosperity of Cities. ; 2013.

2. WHO and UN-HABITAT: Hidden cities: unmasking and overcoming health inequities in urban settings. In Book Hidden cities: Unmasking and Overcoming Health Inequities In Urban Settings. Geneva: The WHO Centre for Health Development, Kobe, and the United Nationas Human Settlements Programme (UN-HABITAT); 2010.

3. Sclar ED, Garau P, Carolini G: The 21st century health challenge of slums and cities. Lancet 2005, 365:901-903.

4. Riley LW, Ko Al, Unger A, Reis MG: Slum health: diseases of neglected populations. BMC 2007, 7:2.

5. Unger A, Riley LW: Slum health: from understanding to action. PLOS Med 2007, 4:1561-1566.

6. Smit W, Hancock T, Kumaresen J, Santos-Burgoa C, Sanchez-Kobashi Meneses R Friel S: Toward a research and action agenda on urban planning/design and health equity in cities in low and middle-income countries. J Urban Health 2011, 88:875-885

7. Solar OIA: A conceptual framework for action on the social determinants of health. In Book A Conceptual Framework For Action On The Social Determinants Of Health. Geneva: WHO; 2010.

8. WHO: Global status report on noncommunicable diseases 2010. In Book Global status report on noncommunicable diseases 2010. Geneva: World Health Organization; 2011.

9. Huynen MM, Vollebregt $L$, Martens P, Benavides BM: The epidemiologic transition in Peru. Rev Panam Salud Publica 2005, 17:51-59.

10. Huicho L, Trelles M, Gonzales F, Mendoza W, Miranda J: Mortality profiles in a country facing epidemiological transition: an analysis of registered data. BMC Public Health 2009, 9:47.

11. Miranda JJ, Gilman RH, Garcia HH, Smeeth L: The effect on cardiovascular risk factors of migration from rural to urban areas in Peru: PERU MIGRANT study. BMC Cardiovasc Disord 2009, 9:23.

12. Miranda JJ, Gilman RH, Smeeth L: Differences in cardiovascular risk factors in rural, urban and rural-to-urban migrants in Peru. Heart 2011, 97:787-796.

13. Davies AR, Miranda JJ, Gilman RH, Smeeth L: Hypertension among adults in a deprived urban area of Peru - undiagnosed and uncontrolled? BMC research notes 2008, 1:2.

14. Jacoby E, Goldstein J, Lopez A, Nunez E, Lopez T: Social class, family, and life-style factors associated with overweight and obesity among adults in Peruvian cities. Prev Med 2003, 37:396-405.

15. LoretdeMola C, Stanojevic S, Ruiz P, Gilman RH, Smeeth L, Miranda JJ: The effect of rural-to-urban migration on social capital and common mental disorders: PERU MIGRANT study. Soc Psychiatry Psychiatr Epidemiol 2012, 47:967-973

16. Robinson CL, Baumann LM, Gilman RH, Romero K, Combe JM, Cabrera L, Hansel NN, Barnes K, Gonzalvez G, Wise RA, Breysse PN, Checkley W: The Peru Urban versus Rural Asthma (PURA) Study: methods and baseline quality control data from a cross-sectional investigation into the prevalence, severity, genetics, immunology and environmental factors affecting asthma in adolescence in Peru. BMJ open 2012, 2:e000421.

17. Weygandt PL, Vidal-Cardenas E, Gilman RH, Avila-Tang E, Cabrera L, Checkley W: Epidemiology of tobacco use and dependence in adults in a poor peri-urban community in Lima. Peru BMC Pulm Med 2012, 12:9.

18. Galvez-Buccollini JA, Paz-Soldan VA, Herrera PM, DeLea S, Gilman RH: Gender differences in sex-related alcohol expectancies in young adults from a peri-urban area in Lima, Peru. Rev Panam Salud Publica 2009, 25:499-505

19. Bernabe-Ortiz A, Benziger CP, Gilman RH, Smeeth L, Miranda JJ: Sex differences in risk factors for cardiovascular disease: the PERU MIGRANT study. PLOS One 2012, 7:e35127.

20. Bernabe-Ortiz A, Gilman RH, Smeeth L, Miranda JJ: Migration surrogates and their association with obesity among within-country migrants. Obesity 2010, 18:2199-2203.

21. Czechowicz JA, Messner AH, Alarcon-Matutti E, Alarcon J, Quinones-Calderon G, Montano S, Zunt JR: Hearing impairment and poverty: the epidemiology of ear disease in Peruvian schoolchildren. Otolanyngol Head Neck Surg 2010, 142:272-277.
22. Escuela Saludable y Ecologica, Lomas de Zapallal. [http://awb-seattle.org/ projects/featured-project/]

23. Henderson RH, Sundaresan $\mathrm{T}$ : Cluster sampling to assess immunization coverage: a review of experience with a simplified sampling method. Bull World Health Organ 1982, 60:253-260.

24. Bennett S, Woods T, Liyanage WM, Smith DL: A simplified general method for cluster-sample surveys of health in developing countries. World Health Stat Q 1991, 44:98-106.

25. WHO: WHO STEPS Instrument for noncommunicable disease risk factor surveillance (STEPS). In Book WHO STEPS Instrument for Noncommunicable Disease Risk Factor Surveillance (STEPS). Geneva: World Health Organization; 2011.

26. WHO: Physical status: the use and interpretation of anthropometry. In Book Physical Status: The Use and Interpretation of Anthropometry. Geneva: World Health Organization; 1995.

27. WHO: Waist circumference and waist-hip ratio: report of a WHO expert consultation, 8-11 December 2008. In Book Waist circumference and Waist-Hip Ratio: Report of a WHO Expert Consultation, 8-11 December 2008. Geneva: World Health Organization; 2011.

28. Medina-Lezama J, Pastorius CA, Zea-Diaz H, Bernabe-Ortiz A, CorralesMedina F, Morey-Vargas OL, Chirinos DA, Munoz-Atahualpa E, ChirinosPacheco J, Chirinos JA, Investigators P: Optimal definitions for abdominal obesity and the metabolic syndrome in Andean Hispanics: the PREVENCION study. Diabetes Care 2010, 33:1385-1388.

29. Harris PA, Taylor R, Thielke R, Payne J, Gonzalez N, Conde JG: Research electronic data capture (REDCap)-a metadata-driven methodology and workflow process for providing translational research informatics support. J Biomed Inform 2009, 42:377-381.

30. Instituto Especializado de Salud Mental "Honorio Delgado - Hideyo Noguchi: Estudio epidemiológico metropolitano en salud mental 2002. In Book Estudio Epidemiológico Metropolitano en Salud Mental 2002, Volume 18. Lima: Instituto Especializado de Salud Mental "Honorio Delgado - Hideyo Noguchi"; 2002.

31. Jain RK, Aras RY: Depression in geriatric population in urban slums of Mumbai. Indian J Public Health 2007, 51:112-113.

32. Dasgupta A, Battala M, Saggurti N, Nair S, Naik DD, Silverman JG, Balaiah D, Raj A: Local social support mitigates depression among women contending with spousal violence and husband's risky drinking in Mumbai slum communities. J Affect Disord 2013, 145:126-129.

33. Gruebner O, Khan MM, Lautenbach S, Muller D, Kramer A, Lakes T, Hostert P: Mental health in the slums of Dhaka - a geoepidemiological study. BMC Public Health 2012, 12:177.

34. Gruebner O, Khan MM, Lautenbach S, Muller D, Kraemer A, Lakes T, Hostert P: A spatial epidemiological analysis of self-rated mental health in the slums of Dhaka. Int J Health Geogr 2011, 10:36.

35. Brashier B, Londhe J, Madas S, Vincent V, Salvi S: Prevalence of selfreported respiratory symptoms, asthma and chronic bronchitis in slum area of a rapidly developing Indian city. Open J Respir Dis 2012, 2:73-81.

36. Haq SA, Darmawan J, Islam MN, Uddin MZ, Das BB, Rahman F, Chowdhury MA, Alam MN, Mahmud TA, Chowdhury MR, Tahir M: Prevalence of rheumatic diseases and associated outcomes in rural and urban communities in Bangladesh: a COPCORD study. J Rheumatol 2005, 32:348-353.

37. Ayah R, Joshi MD, Wanjiru R, Njau EK, Otieno CF, Njeru EK, Mutai KK: A population-based survey of prevalence of diabetes and correlates in an urban slum community in Nairobi. Kenya BMC Public Health 2013, 13:371.

38. Oti SO, van de Vijver SJ, Agyemang C, Kyobutungi C: The magnitude of diabetes and its association with obesity in the slums of Nairobi, Kenya: results from a cross-sectional survey. Trop Med Int Health 2013, 18:1520-1530.

39. Anand K, Shah B, Yadav K, Singh R, Mathur P, Paul E, Kapoor SK: Are the urban poor vulnerable to non-communicable diseases? A survey of risk factors for non-communicable diseases in urban slums of Faridabad. Natl Med J India 2007, 20:115-120.

40. Hussain A, Rahim MA, Azad Khan AK, Ali SM, Vaaler S: Type 2 diabetes in rural and urban population: diverse prevalence and associated risk factors in Bangladesh. Diabet Med 2005, 22:931-936.

41. Singh AK, Mani K, Krishnan A, Aggarwal P, Gupta SK: Prevalence, awareness, treatment and control of diabetes among elderly persons in an urban slum of delhi. Indian Journal Com Med 2012, 37:236-239.

42. Galvez-Buccollini JA, Paz-Soldan V, Herrera P, DeLea S, Gilman RH, Anthony JC: Links between sex-related expectations about alcohol, heavy episodic 
drinking and sexual risk among young men in a shantytown in Lima, Peru. Int Fam Plan Perspect 2008, 34:15-20.

43. Daniel OJ, Adejumo OA, Adejumo EN, Owolabi RS, Braimoh RW: Prevalence of hypertension among urban slum dwellers in Lagos, Nigeria. J Urban Health 2013, 90:1016-1025.

44. Ettarh R, Van de Vijver S, Oti S, Kyobutungi C: Overweight, obesity, and perception of body image among slum residents in Nairobi, Kenya, 2008-2009. Prev Chronic Dis 2013, 10:E212.

45. van de Vijver SJ, Oti SO, Agyemang C, Gomez GB, Kyobutungi C: Prevalence, awareness, treatment and control of hypertension among slum dwellers in Nairobi, Kenya. J Hypertens 2013, 31:1018-1024.

46. Sverdlik A: III-health and poverty: a literature on health in informal settlements. Environ Urbanization 2011, 23:123-155.

47. Oti SO, van de Vijver SJ, Kyobutungi C, Gomez GB, Agyemang C, Van Charante EP M, Brewster LM, Hendriks ME, Schultsz C, Ettarh R: A community-based intervention for primary prevention of cardiovascular diseases in the slums of Nairobi: the SCALE UP study protocol for a prospective quasi-experimental community-based trial. Trials 2013, 14:409.

doi:10.1186/1472-698X-14-19

Cite this article as: Heitzinger et al:: A community-based cluster randomized survey of noncommunicable disease and risk factors in a peri-urban shantytown in Lima, Peru. BMC International Health and Human Rights 2014 14:19.

\section{Submit your next manuscript to BioMed Central and take full advantage of:}

- Convenient online submission

- Thorough peer review

- No space constraints or color figure charges

- Immediate publication on acceptance

- Inclusion in PubMed, CAS, Scopus and Google Scholar

- Research which is freely available for redistribution 